\title{
Factors that Affect the Quality of Healthcare Services in Ethiopia
}

\author{
Berhanu Endeshaw \\ Department of Management, Kotebe Metropolitan University, Addis Ababa, Ethiopia
}

\section{Email address:}

berhanu22012@gmail.com

\section{To cite this article:}

Berhanu Endeshaw. Factors that Affect the Quality of Healthcare Services in Ethiopia. Science Journal of Business and Management. Vol. 9, No. 3, 2021, pp. 186-196. doi: 10.11648/j.sjbm.20210903.15

Received: April 29, 2021; Accepted: July 6, 2021; Published: July 15, 2021

\begin{abstract}
Service-quality dimensions are controversial and they continue to debate about the factors (also called determinants) and indicators (also called criteria). Service quality still constitutes an undecided critical issue. This gives rise to challenges as far as the improvement of healthcare service-quality is concerned, and there Ethiopia is no exception. The main objective of this study is to identify the factors that affect the quality of healthcare services in Ethiopia. This study used a qualitative research design. The study was initially investigated through a comprehensive review of the extant literature regarding factors and indicators of healthcare service quality. Then focus-group discussions and panel of experts were conducted for confirming the indicators identified and also exploring additional indicators as per the Ethiopian context. Lastly, indicators were grouped in to factors. Three hospitals administered by the Federal Ministry of Health, Ethiopia, namely, St. Paul s, Tikur Anbessa and ALERT hospitals. Managers, healthcare providers, patients and support staff were participated in the study. This study came up with 60 indicators, 36 indicators were generated from the literature review, and the rest were added by the focus groups and the panel of experts. The panel of experts grouped these indicators into 6 factors, namely tangibles, technical quality, personal care, assurance, medical-administration procedures, and reliability. The factors and indicators of factors identified in this study were the unique characteristics of the healthcare services in Ethiopia. It could also be a basis for every country and even a basis for every organization in the developing world.
\end{abstract}

Keywords: Healthcare Service Quality, Factors, Indicators of Factors, SERVQUAL, SERVPERF

\section{Introduction}

Quality seems to be varying understanding and definitions, and even well-known authors define quality in different ways and views. Some of the influential contributors and thought leaders defined quality as follows: Crosby's definition focused entirely on quality as conformance to specification, while Deming, Feigenbaum, and Ishikawa's defined quality as products and services that need to satisfy customers' in accordance with their needs and expectation. Juran's definition however rather incorporated specification and customer satisfaction simultaneously.

The definition of quality has not yet given the same results throughout [1]. These authors emphasised the fact that irrespective of the time or context whereby quality is inspected, quality has got numerous definitions. The nature of service quality can be elusive because customers needs, and expectations are always changing. To keep up with the change, quality must be constantly managed and continually improved [2].

Distinct healthcare characteristics such as intangibility, heterogeneity and simultaneity make it difficult to define and measure quality $[3,4]$, and the complex nature of healthcare, the different interests of healthcare providers in delivering healthcare and the requirement of ethical consideration subjected to a problem [5], Due to the difference in background, experience, skill and personal characteristics of healthcare professionals, the service given for a patient varies [4].

Every day, patients are negatively affected by healthcare processes and systems, and yet there has not been a significant reduction in the severity and frequency of such effects [6]. Despite attempts to improve service quality, it is shown in the literature that no consensus has been reached on the definition, dimensions and criteria of quality [7].

Overall, identification of service-quality dimensions is a 
controversial and important issue, but on a number of these dimensions, no general consensus has yet been reached. Although all researchers agree that the structure of service quality is multidimensional and complex in nature [8] they continue to debate about the factors (also called determinants) and indicators (also called criteria) of service quality, which still constitute an undecided critical issue. The aforegoing gives rise to challenges as far as the improvement of healthcare service-quality is concerned, and there Ethiopia is no exception.

Service quality becomes even more important in sectors such as healthcare, where the patients often have limited or no information about the technical aspect of the service offered. In these conditions, the functional part becomes more important to depend on [9, 10].

The technical aspect that can be generated from providers of healthcare services was not included in SERVQUAL and in the model drawn from it [11].

Technical quality emphases on skills being precise in the procedures and health diagnosis, while functional quality refers to the means through which the services are delivered to patients [9]. Thus, in order to understand the quality given for the patients, the technical dimensions need to be considered. In this connection, [12] stated that to be successful in the long period, organization requires both aspects.

As it is known, quality-improvement discrepancies can be mitigated by integrating different functions and the thinking and design of role-players [13]. Consequently, this study focuses on technical and functional quality dimensions that can lead to better healthcare-service outcomes.

How service quality could and should be measured remained a subject open to discussion [14]. The conceptualisation and measurement of service quality to be a fundamental issue in service-quality research $[15,16]$, and it is shown by the literature that service quality has been agreed upon to be a multidimensional concept $[8,17]$.

Therefore, in order to measure and identify measuring gaps, the factors and indicators of a framework need to be identified first. Identification of the factors of service quality is one of the burning issues and is paramount for measuring, controlling and improving the quality of service. This is even more crucial in the case of healthcare services. Unless gaps are identified at an early stage and in an accurate manner, simply providing a raft of general interventions will not meet the real health needs of the people.

To effectively measure service quality, industry-specific service-quality indicators should be developed since every industry has its own features [18-20]. It is also further observed that the outcome of service quality and its measurement strongly depends on the types of service setting, situations, time, needs, and other factors [19]. These further add to the complexity of what service quality is.

In addition to the above, even customers' expectations of a particular service are also changing with time, environment and etc. This demands a continuous modification in the existing concepts of service quality $[2,21]$. There is therefore a need for further empirical studies that can be applied on service quality.

It has been identified in the literature on consumer behaviour and marketing that a consumer-behaviour- or perception-related model may not be generalised to all contexts [22, 23]. A service-quality model may also be implemented to only certain contexts [24, 25]. Some researchers argued that service-quality measurement is affected by the service context [25]. The above therefore implies that a model developed for one context may not be applicable to other contexts.

Most researches on a model for measuring the quality of healthcare services were done in the context of developed countries [26], however, it is fairly limited in number in developing countries. It is acknowledged by researchers and they are trying to explore its appilicability in their real environment [27].

It is also clearly noted in the literature that frameworks developed for measuring the quality of services in developed countries may not be suitable for developing countries. This is due to differences in culture and the economy [7, 28-31]. These authors pointed out that the era of "one size fits all" as a standardised framework for undifferentiated customers was over.

The perceptions of the quality of service encounters are influenced by cultural values [31]. Measurement of the quality of healthcare services should have international and crosscultural studies on healthcare as a control variable [33].

Service-quality dimensions developed in one culture may not be appropriate in another culture [34], that the models that work in Western culture, for instance may not work in another [35]. It is also state that it is common knowledge that service quality dimensions developed in accordance with the context of that country culture can have an influence on the quality of services [26].

Even though some studies shed light on the applicability of those frameworks and tools in improving the quality of healthcare, the inappropriateness of those instruments as well as the lack of empirical evidence (grounded in reality) did not lead to a significant improvement in the healthcare system of the developing continent of Africa in general [36] and Ethiopia in particular.

It came to the conclusion that models for the measuring of service quality developed in some specific countries needed to be checked whether it works for other countries and modify [37]. This means that quality-measurement instruments developed by the Western world may not necessarily be congruent with the healthcare services of developing countries. In order to generate applicable instruments, researchers are starting to concentrate on their own specific healthcare settings [7, 30].

In order to develop applicable quality measurement, quality indicators for specific healthcare settings need to be developed. Many healthcare settings increasingly make use of quality indicators for measuring, comparing and increasing the quality of care [38]. Despite efforts made by many scholars, no consensus on the definition, factors and 
indicators of the quality of healthcare services that would form a framework has as yet been reached [7, 39]. This serves as a reminder that the existing factors and indicators that form a framework do not suffice for measuring the quality of healthcare services.

Patients, providers, regulators, payers and suppliers can all identify indicators that can help measure healthcare quality. As long as the definition, measurement and improvement of healthcare quality should take heed of the perspectives and priorities of such healthcare stakeholders [40].

Discrepancies in quality improvement can therefore be lessened by considering the thinking of the role-players concerned [13]. This implies that the input of both technicalquality indicators (healthcare providers) and functionalquality indicators (patients) can be used for developing an appropriate framework for measuring the quality of healthcare services.

This study was designed to integrate the views of the stakeholders concerned: that is, healthcare providers can now provide technical-quality indicators, while patients can provide functional-quality indicators.

Despite the growing importance of quality healthcare, Africa in general and Ethiopia in particular seem to be unaware of the quality improvement that needs to be done and the management decisions that need to be made in that regard [41].

Thus, the absence of empirical evidence on how to build and get a better understanding of where and why there are failures and strategies to minimise the occurrence, impact and severity of service failure make service delivery a debatable matter [21, 41].

The root cause of the above is that healthcare organisations are unable to scrutinise which factors and indicators are useful to measure and needed to focus on for improving the quality of their healthcare services. The aim of this study was therefore to identify healthcare-quality factors and indicators that form an appropriate tool for measuring the quality of healthcare services in Ethiopia as per the culture and economy of the country.

\subsection{Research Question}

What are the factors that affect the quality of healthcare services in Ethiopia?

\subsection{Purpose of the Study}

The main purpose of this study is to identify the factors that affect the quality of healthcare services in Ethiopia.

The specific objectives of this study were to:

1) Identify indicators used to measure the quality of healthcare services from the extant literature.

2) Confirm the indicators identified and explore additional indicators as per the Ethiopian context using focus group discussion.

3) Confirm the indicators identified (by the focus group) and add if there is any and group these indicators into factors using a panel of experts.

\section{Design/Methodology/Approach}

\subsection{Research Design and Strategies}

This study used a qualitative research design. The study was initially investigated through a comprehensive review of the extant literature regarding factors and indicators of healthcare service quality. Then focus-group discussions were conducted for confirming the indicators which are identified form the review of the literature and identifying additional indicators as per the Ethiopian context. Later a panel of experts was conducted for confirming the indicators which are identified by the focus group, and then additional indicators were explored. Lastly, indicators were grouped. In general, a combination of three methods could lead to particularly robust and vibrant inquiries.

\subsection{Unit of Analysis}

Three of the five hospitals administered by the Federal Ministry of Health [FMOH] and employees working and patients receiving services in these hospitals were considered to be units of analysis. The names of these hospitals are the St. Paul's, Tikur Anbessa and ALERT hospitals.

The reason why these hospitals were selected is that they have been carrying out wider and more types of service than the other healthcare organisations. They form a large and complex system in which decisions are made and implemented across organisational layers and professional groups. Moreover, they have for many years been delivering health services and admitting very many patients from every corner of the country through the referral systems. They are also unique in that many of their patients and staff had different service-delivery experience at different levels of healthcare-service organisations before coming to these particular hospitals. The underlying criterion for selecting these hospitals was that they constituted a fair representation of all the other healthcare organisations in Ethiopia. This paved the way for the researcher to get a complete understanding of the information received from the respondents.

The respondents of this study comprised top-, middle- and first-level managers, patients or their attendants, healthcare providers, and support staff were working and receiving services in the selected hospitals. The units of analysis were selected for the following reasons:

Hence, each one of the above-mentioned units of analysis has its own interest in and opinions on the factors and indicators used for measuring the quality of healthcare services. Although it is assumed that patients can understand the functional quality of healthcare services, they generally have no knowledge of the technical aspects [42]. It is therefore for the employees of healthcare organisations to provide information about the technical quality of the healthcare services.

It could be said that if a healthcare organisation wishes to be successful in the long run, both its functional and its technical qualities must be considered to improve the quality of its services [43, 44].

If the above units of analysis were to be integrated, it 
would result in a complete and appropriate framework for measuring the quality of healthcare services.

\subsection{Data-collection Instruments and Sampling Techniques}

The research instruments used in this study were an indepth literature review, focus group discussions and a panel of experts.

Purposive and snowball sampling were used. Purposive sampling was used for selecting a sample of focus-group participants including managers, healthcare providers, patients and support staff. Top-level managers, experienced health specialists, experienced support staff and patients all participated in this research. The patients were all in- and out-patients over the age of 18 years who were receiving healthcare services during the period of data collection. There were seven homogeneous focus groups in each specialised hospital. Group 1 consisted of top-, middle- and first-level managers; group 2 included physicians and general practitioners; group 3 consisted of nurses and health officers; group 4 included laboratory, pharmacy and radiology professionals; group 5 consisted of support staff, group 6 consisted of inpatients, and group 7 consisted of out-patients. Each focus group was expected to contribute additional distinct indicators that were considered to be fundamental for measuring the quality of healthcare services in Ethiopia. On average, each focus-group discussion took about 60 to 90 minutes. The discussions were held in a conference room during the period November 2015 to January 2016.

What makes the selection of panel members unique is that each member has to have the expertise of being able to improve the quality of healthcare services. The members of the panel are selected through nomination (called snow-ball or chain-referral sampling).

The researcher was referred to two experts working in the ministry and in the hospitals by prominent officials in the FMOH. The researcher then asked these experts to recruit other experts in the quality of healthcare services.

The researcher also asked the panel of experts to provide relevant service- quality indicators that had not yet been captured through the focus- group discussions and the literature review. This helped to refine and verify the scaledevelopment process and to discard irrelevant indicators. It also provided an opportunity for additional indicators for measuring the quality of healthcare services that had not been captured through the focus-group discussions and the literature review. On average, the panel discussion took about 60 to 90 minutes. The panel of experts met in February 2016.

\subsection{Sample Size and Sample}

Here it needs to be noted that the existing literature provided general information on the construct that was relevant for generating a broad initial set of items. The focus groups and the panel of experts were used for drawing additional indicators from the output of the literature review and the real environment.

There were about 4 to 12 homogeneous participants per focus group. According to [45, 46], It is an accepted practice to have three or four focus groups consisting of individuals from each type or category. Hence there were a total of 28 $(7 * 4=28)$ focus groups. The participants of the groups were generally chosen because of their relevance to the topic and the concept of quality of healthcare services. The task of the panel of experts (estimated from 4 to 6) was to confirm the indicators identified.

\subsection{Analytical Procedure}

Analysis occurs within the descriptive and thematic text analysis. First, themes and specific statements also called factors (dimensions), and indicators (criteria) were obtained from a literature review. Secondly, the focus groups proposed factors and indicators of quality in the context of the Ethiopian healthcare services. The qualitative data collected during all the focus-group sessions were analysed using frequencies, rankings, and content analysis.

The analysis of the data for this study began by reducing the data into categories, grouping and regrouping data written on individual cards and drawing conclusions about various categories. The researcher repeated this process as the different focus-group discussions were completed.

The researcher's independent coding of the data was compared with the coding's of the focus groups. If the coding's differed, they were discussed until consensus was reached. The panellists then reviewed the data and checked the categories.

The resulting categories were analysed in relation to the results of the literature review in order to see how well the set of data obtained through the literature review represented the patterns in the set of coded data. New patterns would emerge from the data that could be added to the results of the literature review.

The insights gained from the focus-group discussions were used not only for generating indicators, but also for confirming and reconfirming the factors and indicators identified and examining the data in relation to the theoretical factors previously identified through the literature review. Then the panel of experts purified and verified the indicators and discarded those indicators that were seen to be repetitive, and could affect the scale development process.

The qualitative study, particularly the focus-group discussions and the deliberations of the panel of experts, was expected to uncover new indicators not captured in the literature as per the culture and economy of the country.

The qualitative analysis yielded appropriate factors and indicators about the real situation in the selected healthcare organisations.

\section{Results}

\subsection{Quality Factors, Indicators and Where They Are Discussed in the Literature}

Service-quality-measurement factors and indicators differ from study to study. Thus, further exploration, testing and 
validation is required before anyone factor can be accepted as a factor underlying the construct of quality of healthcare services.

Also, the majority of studies were done in the context of a developed country and could not be generalised to the context of a developing country, such as Ethiopia.

It was argued that the dimensions used to measure the quality of service developed in one culture might not be appropriate to other culture [33]. This reminds that it depends on the culture of every country.

The roblems of validity regarding the quality of services models can take place to all cultures for three reasons [47], namely, (1) misrepresentations of the construct; (2) misuse of method; and (3) misrepresentations of items. They explained that researchers should take into consideration the above bias in developing a model.

There is evidence of many researchers have adopted, adapted and developed a service-quality model in accordance with the context of their particular healthcare services. The research outputs of such authors have produced different quality factors and indicators, as seen in Table 1.

Table 1. Quality factors and indicators, as found in the literature.

\begin{tabular}{|c|c|c|}
\hline Author (s) & Service-quality factors and indicators & Outcome/Model/Application \\
\hline Donabedian (1980) & $\begin{array}{l}7 \text { factors: efficacy, effectiveness, efficiency, optimality, acceptability, legitimacy } \\
\text { and equity }\end{array}$ & In healthcare studies \\
\hline Maxwell (1984), in the UK & $\begin{array}{l}6 \text { factors: effectiveness, efficiency, acceptability, accessibility, equity and } \\
\text { relevance }\end{array}$ & In healthcare studies \\
\hline $\begin{array}{l}\text { Parasuraman, et al (1985), in the } \\
\text { USA }\end{array}$ & $\begin{array}{l}22 \text { items grouped into } 5 \text { major factors, namely reliability, responsiveness, } \\
\text { tangibles, assurance and empathy }\end{array}$ & $\begin{array}{l}\text { Developed the SERVQUAL model } \\
\text { for services }\end{array}$ \\
\hline 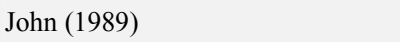 & 4 factors in healthcare: curing, caring, access and physical environment & In healthcare studies \\
\hline Cunningham (1991), in the USA & Clinical quality, patient- and economics-driven quality & In healthcare studies \\
\hline Headley and Miller (1993) & $\begin{array}{l}6 \text { factors: dependability, empathy, reliability, responsiveness, tangibles and } \\
\text { presentation }\end{array}$ & $\begin{array}{l}\text { Used original SERVQUAL items for } \\
\text { medical services }\end{array}$ \\
\hline $\begin{array}{l}\text { Peyrot, Cooper and Schnapf } \\
\text { (1993) }\end{array}$ & $\begin{array}{l}3 \text { factors: (1) staff behaviour; (2) pre-examination comfort; and (3) examination } \\
\text { comfort }\end{array}$ & In healthcare studies \\
\hline Gabott and Hogg (1994) & $\begin{array}{l}6 \text { factors: (1) service range, (2) empathy), (3) physical access, (4) doctor- } \\
\text { specific, (5) situational, and (6) responsiveness }\end{array}$ & In healthcare studies \\
\hline Tomes and $\mathrm{Ng}$ (1995), in the UK & $\begin{array}{l}8 \text { factors: empathy, understanding of illness, mutual respect, religious needs, } \\
\text { dignity, food and physical environment }\end{array}$ & $\begin{array}{l}\text { In healthcare studies, using the Gap } \\
\text { model }\end{array}$ \\
\hline Zairi (1998), in the UK & $\begin{array}{l}\text { Deming Prize, Malcolm Baldridge National Quality Award (MBNQA), } \\
\text { European Quality Award, and the George M Low NASA quality award }\end{array}$ & In healthcare studies \\
\hline Gross and Nirel (1998), in Ireland & Accessibility, structure, atmosphere and interpersonal relations & In healthcare studies \\
\hline $\begin{array}{l}\text { Shemwell and } \\
\text { Yavas (1999) }\end{array}$ & $\begin{array}{l}3 \text { factors: search attributes ( } 5 \text { indicators), credence attributes ( } 4 \text { indicators), } \\
\text { experience attributes ( } 5 \text { indicators) }\end{array}$ & $\begin{array}{l}\text { Hospital service quality (perception- } \\
\text { only scores) in the USA }\end{array}$ \\
\hline Ovretveit (2000a), in Sweden & Client, professional and management quality & In healthcare studies \\
\hline Drain (2001) & $\begin{array}{l}4 \text { factors: (1) care provider, (2) access to care, (3) office visit, and (4) personal } \\
\text { issues }\end{array}$ & In healthcare studies \\
\hline $\begin{array}{l}\text { Lim and Tang (2000), in } \\
\text { Singapore }\end{array}$ & Parasuraman, et al (1985) 5 factors plus accessibility/affordability & $\begin{array}{l}\text { Applied SERVQUAL in healthcare } \\
\text { services }\end{array}$ \\
\hline $\begin{array}{l}\text { Sower, et al } \\
(2001) \text {, in the USA }\end{array}$ & $\begin{array}{l}8 \text { factors: respect and caring (26), effectiveness and continuity (15), } \\
\text { appropriateness (15), information ( } 7) \text {, efficiency (5), effectiveness - meals (5), } \\
\text { first impression (1), staff diversity (1) }\end{array}$ & Perception-only scores \\
\hline Trucker and Adams (2001) & Caring, empathy, reliability and responsiveness & $\begin{array}{l}\text { Applied SERVQUAL in US } \\
\text { hospitals }\end{array}$ \\
\hline $\begin{array}{l}\text { Jabnoun and Chaker (2003), in the } \\
\text { UAE }\end{array}$ & $\begin{array}{l}\text { Reliability, responsiveness, supporting skills, empathy and tangibles for } \\
\text { comparing service-quality perceptions in private and public hospitals }\end{array}$ & Applied SERVQUAL \\
\hline $\begin{array}{l}\text { Boshoff and Gray (2004) in South } \\
\text { African hospitals }\end{array}$ & $\begin{array}{l}\text { Communication, tangibles, empathy of nursing staff, assurance, responsiveness } \\
\text { of administrative staff, security and physician responsiveness }\end{array}$ & Applied SERVQUAL in healthcare \\
\hline Iyer and Muncy (2004) & $\begin{array}{l}\text { Patients of high-trust groups: reliability and responsiveness whereas Patients of } \\
\text { the low-trust groups: empathy and tangibles }\end{array}$ & Applied SERVQUAL in healthcare \\
\hline $\begin{array}{l}\text { Kilbourne, et al (2004), in the } \\
\text { USA and the UK }\end{array}$ & 4 factors: tangibles, reliability, responsiveness and empathy & Applied SERVQUAL \\
\hline Herstein and Gamliel (2006) & 5 factors of SERVQUAL plus private branding & Applied SERVQUAL in healthcare \\
\hline $\begin{array}{l}\text { Zineldin (2006), in Egypt and } \\
\text { Jordan }\end{array}$ & $\begin{array}{l}5 \text { factors: technical aspects, a functional infrastructure, interaction and } \\
\text { atmosphere qualities and services }\end{array}$ & $\begin{array}{l}2 \text { existing models -technical/functional } \\
\text { and SERVQUAL }\end{array}$ \\
\hline Dagger, et. al (2007) & $\begin{array}{l}\text { Interpersonal quality, technical quality, environment quality, and administrative } \\
\text { quality }\end{array}$ & In healthcare studies \\
\hline Raja, et al (2007), in India & MBQNA and EFQM & In healthcare studies \\
\hline Wilkins, et al (2007) & $\begin{array}{l}3 \text { factors: physical product ( } 3 \text { sub-dimensions, } 13 \text { items), service experience ( } 3 \\
\text { sub-dimensions, } 13 \text { items), quality food and beverage ( } 4 \text { items) }\end{array}$ & $\begin{array}{l}\text { Hospital services in Australia } \\
\text { (perception-only scores) }\end{array}$ \\
\hline Arasli, et al (2008) & Empathy, giving priority to the needs of in-patients, relationships between staff & In healthcare studies \\
\hline
\end{tabular}




\begin{tabular}{|c|c|c|}
\hline Author (s) & Service-quality factors and indicators & Outcome/Model/Application \\
\hline Akter, et al (2008) & $\begin{array}{l}\text { and patients, professionalism of staff, food, and the physical environment } \\
\text { Responsiveness, assurance, communication, discipline (adherence to rules and } \\
\text { regulations) and baksheesh (additional compensation) }\end{array}$ & $\begin{array}{l}\text { Adopted and adapted SERVQUAL } \\
\text { in Bangladesh }\end{array}$ \\
\hline $\begin{array}{l}\text { Ramsaran-Fowder (2008), } \\
\text { in Mauritius }\end{array}$ & Reliability, fair and equitable treatment & $\begin{array}{l}\text { Developed a new instrument called } \\
\text { PRIVHEALTHQUAL based on } \\
\text { factor analysis }\end{array}$ \\
\hline $\begin{array}{l}\text { Reidenbach and Sandifer- } \\
\text { Smallwood (1990) }\end{array}$ & $\begin{array}{l}\text { Patient confidence, business competence, treatment quality, support services, } \\
\text { physical appearance, waiting time, and empathy }\end{array}$ & $\begin{array}{l}\text { Non-SERVQUAL studies of } \\
\text { healthcare }\end{array}$ \\
\hline Andaleeb (1998) & 5 Factors: communication, cost, facility, competence, and demeanour & $\begin{array}{l}\text { Non-SERVQUAL studies of hospital } \\
\text { services }\end{array}$ \\
\hline Hasin, et al (2001) & Communication, responsiveness, courtesy, cost and cleanliness & Non-SERVQUAL studies of healthcare \\
\hline $\begin{array}{l}\text { Otani and Kurz (2004), in the } \\
\text { USA }\end{array}$ & $\begin{array}{l}\text { Admission process, physician care, nursing care, compassion for family/friends, } \\
\text { pleasantness of surroundings and discharge process }\end{array}$ & $\begin{array}{l}\text { Non-SERVQUAL studies of hospital } \\
\text { services }\end{array}$ \\
\hline Rose, et al (2004) & $\begin{array}{l}\text { Interpersonal aspect, patient education, cost, technical aspect, outcome of the } \\
\text { care, access time, amenities and social support }\end{array}$ & $\begin{array}{l}\text { Non-SERVQUAL studies of } \\
\text { healthcare }\end{array}$ \\
\hline Cronin and Taylor (1992) & Adapted Parasuraman, et al (1985) items using performance-only paradigm & Developed the SERVPERF model \\
\hline Jun, et al (1988) & $\begin{array}{l}\text { Identified } 11 \text { factors of healthcare quality. } 8 \text { of these were part of Parasuraman } \\
\text { et al's (1985) model (i.e. tangibles, courtesy, reliability, communication, } \\
\text { competence, understanding the customer, and access responsiveness). Other } 3 \\
\text { dimensions were caring, patient outcomes and collaboration }\end{array}$ & $\begin{array}{l}\text { Adapted SERVQUAL } \\
\text { for healthcare }\end{array}$ \\
\hline Carman (1990) & $\begin{array}{l}9 \text { factors: admission service, tangible accommodation, tangible food, tangible } \\
\text { privacy, nursing care, explanation of treatment, access and courtesy afforded to } \\
\text { visitors, discharge planning and patient accounting }\end{array}$ & $\begin{array}{l}\text { Arrived at a different dimensional } \\
\text { structure while using the } \\
\text { SERVQUAL scale in a study about } \\
\text { hospitals }\end{array}$ \\
\hline Carman (2000), in the USA & $\begin{array}{l}2 \text { factors of hospital service, namely technical and interpersonal aspects. } \\
\text { service-quality factors for hospitals: health-personnel practices and conduct, }\end{array}$ & In healthcare studies \\
\hline Baltussen, et al (2002) & $\begin{array}{l}\text { adequacy of resources and services, healthcare delivery, and financial and } \\
\text { physical accessibility of care. }\end{array}$ & In healthcare studies \\
\hline $\begin{array}{l}\text { Teng, Ing, Chang \& Chung (2007), } \\
\text { in Taiwan }\end{array}$ & $\begin{array}{l}\text { Needs management, assurance, sanitation, customisation, convenience and } \\
\text { quiet, attention }\end{array}$ & In a hospital \\
\hline Aagja and Garg (2010) & $\begin{array}{l}24 \text { indicators with } 5 \text { major factors used for measuring the quality of public hospitals: } \\
\text { admission, medical service, overall service, discharge and social responsibility }\end{array}$ & $\begin{array}{l}\text { Developed a public- hospital } \\
\text { service-quality model (PubHosQual) }\end{array}$ \\
\hline Yeşilada and Direktör (2010) & Reliability/confidence, empathy, tangibles & $\begin{array}{l}\text { Public and private hospitals in } \\
\text { northern Cyprus }\end{array}$ \\
\hline $\begin{array}{l}\text { Camilleri and O'Callaghan 1998), } \\
\text { in Malta }\end{array}$ & $\begin{array}{l}6 \text { Factors, namely (1) admission process, (2) attitudes of medical staff (doctors), } \\
\text { (3) attitudes of nursing officers, (4) ward/hospital environment, (5) patients' } \\
\text { amenities/facilities, and (6) discharge planning and coordination }\end{array}$ & $\begin{array}{l}\text { Developed HEALTHQUAL for } \\
\text { healthcare services }\end{array}$ \\
\hline Juwaheer and Kassean (2006) & $\begin{array}{l}\text { Patients' perceptions of ward/hospital environment, patients' perceptions of } \\
\text { medical staff (doctors), and patients' perceptions of nursing officers }\end{array}$ & $\begin{array}{l}\text { Adapted a version of the } \\
\text { HEALTHQUAL model } \\
\text { in Mauritius }\end{array}$ \\
\hline Miranda, et al (2010) in Spain & $\begin{array}{l}\text { Model assumed } 4 \text { interrelated, first-order factors: healthcare-staff attributes, } \\
\text { efficiency measures, attributes of non-healthcare-staff and facilities. } \\
\text { Meet disease burdens; optimise care and cost; use knowledge to continuously }\end{array}$ & $\begin{array}{l}\text { Adapted the HEALTHQUAL } \\
\text { measuring functional quality only }\end{array}$ \\
\hline Azam, et al (2011) & $\begin{array}{l}\text { improve healthcare quality; incorporate core and associated supportive quality } \\
\text { managerial levels; address priority areas to achieve optimal critical care for } \\
\text { casualty cases, operation-room/theatre and intensive-care-unit services; and use } \\
\text { clinical governance to improve service structure, process and outcome }\end{array}$ & $\begin{array}{l}\text { Health Care Establishment (HCE) } \\
\text { integrated model, validated by } \\
\text { healthcare staff }\end{array}$ \\
\hline Narang (2011), in India & $\begin{array}{l}\text { Healthcare delivery, interpersonal and diagnostic aspect of care facility, health- } \\
\text { personnel conduct and drug availability, financial and physical access to care }\end{array}$ & $\begin{array}{l}\text { In healthcare studies (Public Health } \\
\text { Care Centre) }\end{array}$ \\
\hline Itumalla, et al (2014), in India & $\begin{array}{l}\text { Medical service, nursing service, support services, administrative services, } \\
\text { patient safety, patient communication, and hospital infrastructure }\end{array}$ & $\begin{array}{l}\text { Developed the HospitalQual } \\
\text { theoretical model }\end{array}$ \\
\hline
\end{tabular}

Source: Existing literature

\subsection{Proposed Conceptual Framework}

Through comparison, common and vital factors and indicators were identified, while repetitive factors and indicators were excluded. The review and synthesis of the existing literature came up with six major groups as factors (dimensions) of healthcare service quality, with altogether 36 indicators (criteria) under those factors (dimension) as shown below:

i. Tangibles, including physical facilities, equipment, personnel and means of communication, and the appearance of the personnel involved

ii. Technical qualities, including professional and 
technical quality (medical care, apparatus used and outcome)

iii. Personnel care, including empathy, caring, responsiveness of line and support staff (willingness to help customers and provide prompt service), support service, food, noise, room temperature, privacy, cleanliness, explanation of treatment

iv. Assurance, including competency (knowledge), quality of treatment, courtesy and security, communication, credibility, access (waiting time), pleasantness of surroundings and patient confidence

v. Medical-administration procedure, including input (admission process), processes of clinical care, output (discharge process), patient outcome (pain relief, lives saved, or gained a better outlook on life), collaboration and social responsibility (service environment)

vi. Reliability, fairness and equity

The constructs obtained from the literature review above were used for judging whether these factors and indicators were needed in the context of healthcare services in Ethiopia. Focus groups and a panel of experts were involved in refining and examining those indicators and adding indicators as per the healthcare services in Ethiopia.

\subsection{Results of the Focus-group Discussion and Panel of Experts}

The plan was to conduct focus-group discussions over 28 groups from seven strata. However, when 22 groups could not produce any new indicators, it was agreed that saturation (i.e. the point where no more information could be added to the existing ranges of ideas (referred to as indicators in this study) had been reached [45].

The following questions were raised during the focus-group discussions and indicators were identified and later verified and put into groups by a panel of experts, as shown below.

Question 6

The following questions, one after the other and in that order, were raised to the participants in the focus-group discussion:

i. Over the period that you have been waiting here in the hospital, what, to your mind, jeopardised (i.e. could be considered to be a gap in) the quality of the healthcare services?

ii. What should be considered with regard to, and needs to be improved in, the quality of healthcare services in the hospital?

iii. What should be focused on in order to enhance the quality of healthcare services in general?

After the focus-group discussions, a panel of 6 experts purified the scale by assessing the content and face validity of the perceived indicators.

The purpose of this panel is threefold. First, it is to tap into the insights of experts from healthcare organisations and to identify indicators specific to those organisations that may not have been captured in the literature. Secondly, it is to determine if the respondents felt that the items are relevant and clear in meaning, the latter being tested by a panel of experts who are in the healthcare profession. Thirdly, the items are put into groups by the experts in order to identify the number of dimensions.

The panel refined, verified, and discarded indicators that were seen to be repetitive, and also rephrased some of them.

The panel grouped the 60 indicators that were generated into 6 factors. Of those 60 indicators, 36 were generated from the literature review, and 24 were added after thorough focusgroup discussions and deliberations of the panel of experts, as shown in the excerpts below.

Excerpt vi-tangibles

i. ........visually-attractive and comfortable physical facilities (e.g. waiting room, chairs, tables and amenities)

ii. ..........modern medical equipment

iii. ..............modern means of communication material

iv. ......neatness of healthcare providers

v. ........ cleanliness of support staff

vi. ......... clean washrooms, clean rooms/wards and without any foul smell

vii. ........ location and accessibility of the hospital

viii.number of specialists versus number of patients

ix. ....... quantity of meals provided to patients

x. ........quality of meals provided to patients

xi. appropriateness of medicaments and supplies (e.g. drugs, laboratory reagents, X-ray supplies and cleaning materials)

xii. ......Faulty medical equipment and its repairing

This factor was about to what extent the respondents felt that the hospital catered for their needs and wants. Hence it is the above aspects that need to be measured as far as the quality of healthcare services is concerned.

Excerpt vii - technical quality

i. ....... competency of the specialists

ii. ....... competency of the nurses and other healthcare providers

iii. ..... precautions against the patient and their attendants getting hospital-acquired infections

iv. .........specialists' familiarity with the latest advances in the medical field and how to put them into practice

v. ........nurses' and other healthcare providers' familiarity with the latest advances in the medical field and how to put them into practice

vi. ............mindfulness of patients' security

vii. teamwork among employees

viii....... whether the administering of medication is up to standard

This factor pertains to the technical aspects of healthcare service-provision to patients. Healthcare providers are expected to provide patients with services of a high technical standard so as to improve the quality of services. This area therefore needs to be measured in order to find gaps so that corrective measures may be taken.

Excerpt viii - personnel care

This is a combination of empathy and responsiveness. a Empathy

i. ........ individual attention given by the hospital 
ii. ..........convenience of operating hours

iii. .........personnel attention given by staff

iv. ....... level of interest shown by the healthcare providers

v. .... whether the hospital knows about the specific needs of its patients

vi. ...... whether the hospital cares for its patients

b Responsiveness

i. ......whether patients are informed of which date and at what time service is available

ii. ......ability of the healthcare providers to give prompt service

iii. ......willingness to help patients seen by healthcare providers

iv. ...... whether the healthcare providers address patients' requests in an appropriate manner

v. ....... whether the healthcare providers never are too busy to address patients' requests

vi. ....... whether the support staff is kind-hearted

vii. .......whether the support staff attend to patients' problems

viii...... whether there is an improvement in time spent by patients in the waiting area before being seen by their doctor

ix. ......... whether there is an improvement in the time patients spend with their doctor

Personnel care is one of the factors identified for measuring to what extent patients' needs and wants with respect to empathy and responsiveness are met. Hence this factor is all about how much attention is given to patients and the provision of services within a short period of time.

Excerpt ix-assurance

i. whether the healthcare providers are competent to answer patients' questions

ii. whether the treatment given by the healthcare providers is of a fully-fledged nature

iii. whether the specialists treat their patients in a courteous manner

iv. whether the support staff treat their patients in a courteous manner

v. whether the specialists have good communication skills

vi. whether the specialists provide credible services

vii. whether there is speedy access to the hospital services

viii. whether the hospital has pleasant surroundings

ix. whether the specialists are trust-inspiring

Assurance pertains to employees' competency as far as knowledge, politeness to patients and the delivery of better services are concerned.

\section{Excerpt $x$ - medical-administration procedures}

Medical-administration procedures constitute combination of inputs, outputs and social responsibility.

a Inputs (admission process)

i. whether patients coming through the referral system are admitted promptly

ii. whether the admission staff are polite

iii. whether admission is given to patients needing emergency treatment.

\section{b Outputs (discharge process)}

i. whether the discharge process is explained to the patients and their family members/attendants

ii. whether the discharge services are done promptly

iii. whether the hospital employees tell patients what to do after discharge (i.e. medicines to be taken, diet restrictions, etc.)

iv. whether there was more pain relief, whether more lives were saved, or whether more patients gained a better outlook on life than before

c Social responsibility (service environment)

i. whether the hospital provides equal treatment, regardless of socio-economic and cultural status

ii. whether the hospital provides good services at a reasonable cost, but not at the expense of quality

iii. whether the hospital employees have a sense of responsibility- that is, they do their rounds on a regular basis, are punctual and sincere, and do not go on strike.

The measurement of quality in order to improve services to patients involves not only the needs and wants of the patients themselves, but also the inputs, outputs and social responsibility of the hospital.

\section{Excerpt xi - reliability}

i. whether the hospital has a reputation of addressing patients' problems on time, and as promised.

ii. Whether healthcare providers are sincerely interested in solving patients' problems

iii. whether the hospital's service providers can be depended on

iv. whether the service providers can provide services correctly the first time around

v. whether the hospital provides services at the time promised

vi. whether the hospital provides fair and impartial services.

Reliability pertains to checking whether the services are in accordance with the promises made to patients. This is done in order to identify aspects that need to be corrected.

Data from excerpts vi to xi were coded and the following themes and patterns started to emerge:

i. tangibles

ii. technical qualities

iii. personal care

iv. assurance

v. medical-administration procedures

vi. reliability

The emerging patterns and themes mentioned above were generated through confirming and reconfirming the factors and indicators to be included in a draft survey instrument.

\section{Discussion}

The question to be answered in this study was as follows: What are the factors that affect the quality of healthcare services in Ethiopia? 


\subsection{The Gap in the Literature Regarding the Conceptualisation and Dimensionality of the Quality of Healthcare Services}

From the discussions of the focus groups and the deliberations of the panel of experts, it was gathered that there was no specific definition for the concept of quality in healthcare services. There was also no consensus on what type of tool (framework) could be used for measuring the quality of such services. Moreover, there were no suggestions for any specific model to be used for measuring the quality of these services. There was however found to be a need for an appropriate framework for specifically measuring the quality of healthcare services.

In order to produce an appropriate framework, both the functional and the technical quality of healthcare services should be included [9, 43, 48].

The above was addressed by asking the following question: Which department or section do you provide services to or receive services from (i.e. with respect to inputs, caring, or any work-related matters)?

It was stated by employees that their department provides services not only to patients, but also to many other departments, and also that their department receives many types of service from many other departments. Moreover, employees can receive services not only with respect to work-related matters, but sometimes they can also be patients when receiving medication from either their own department or other departments.

The above implies that internal customers (employees) not only provide services to patients, but also receive services - for not only work-related, but also personal-healthcare, matters.

Hence, as indicated by [9, 43, 48], internal customers (i.e. employees) can provide both technical and functional quality indicators, and external customers (i.e. patients) can provide functional quality indicators, which suffices for producing an appropriate framework for measuring the quality of healthcare services.

\subsection{Indicators and Factors Found to Be Unique to Healthcare in Ethiopia}

This study was done by first reviewing and synthesising past literature on the quality of healthcare services, and later through focus-group discussions and a panel of experts working in, and receiving services from, three hospitals.

The review and synthesis of extant literature proposed 36 indicators that were grouped into 6 factors. These factors included the following: tangibles, technical qualities, personal care, assurance, medical-administration procedures, and reliability. These factors were refined and further examined through focus-group discussions and by a panel of experts in order to ascertain their suitability for the problem domain with the contextual issues so that they could be more comprehensive and viable.

A process of confirmation and reconfirmation by the focus groups and the panel of experts gave rise to 60 indicators.
These indicators were grouped into 6 factors by the panel. From the total of 60 quality indicators, 36 were generated from the literature review and 24 were added by the focus group and the panel of experts. In general, the qualitative research produced 6 factors, namely tangibles (12 indicators), technical quality (8 indicators), personal care (15 indicators), assurance ( 9 indicators), medical-administration procedures (10 indicators) and reliability (6 indicators).

In this study, the factors and indicators of the quality of healthcare services were subsequently factor analysed and identified. Also identified from the literature review, focusgroups discussions and deliberations of the panel of experts, were the unique characteristics of the healthcare services in Ethiopia.

Thus, managers and employees of healthcare organisations could use as a bais to assess their performance through the factors and indicators identified and could identify improvements needed for increasing the quality of healthcare services in both the context of Ethiopia and similar contexts across the world.

\section{Recommendation}

This study is an inductive approach used for understanding the underpinning theories and for generating indicators pertaining to the quality of healthcare services. The results of this study could be a basis for developing the questionnaire for further evaluating and refining using quantitative study. For instance exploratory and confirmatory factor analysis could that.

\section{Limitation of the Study}

Since the respondents (managers, employees and patients) of this study came from Federal Ministry of Health, the results obtained may have differed for other healthcare organisations such as general hospitals, primary hospitals, health centres and satellite health posts. This could limit the generalizability of the results.

\section{References}

[1] Reeves CA Bednar DA. "Defining quality: alternatives and implications". Academy of Management Review, 1994; 19 (3): 419-445.

[2] Redman A. 'Assessment and accountability'. Journal of Health Services Research and Policy, 2009; 14 (4): 249-250.

[3] Ladhari R. 'A review of twenty years of SERVQUAL research'. International Journal of Quality and Service Sciences, 2009; 1 (2): 172-198.

[4] McLaughlin, C. P. and Kaluzny, A. D. Continuous Quality Improvement in Health Care. 3rd ed. Sudbury, MA: Jones and Bartlett Publishers, 2006.

[5] Eiriz V Figueiredo JA. 'Quality evaluation in healthcare services based on customer provider relationships'. International Journal of Healthcare Quality Assurance, 2005; 18 (6): 404-12. 
[6] Spath P. Introduction to healthcare quality management. USA: Health Administration Press, Chicago; 2009.

[7] Azam M, Rahman Z, Talib F, Singh KJ. "A critical study of quality parameters in health care establishment: developing an integrated quality model". International Journal of Health Care Quality Assurance. 2012; 25 (5): 387-402.

[8] Nam JH, Lee TJ. 'Foreign travelers' satisfaction with traditional Korean restaurants'. International Journal of Hospitality Management, 2011; 30 (4): 982-989.

[9] Zarei A, Arab M, Froushani AR, Rashidian A, Tabatabaei MG 'Service quality of private hospitals: the Iranian patients' perspective. BMC Health Services Research. 2012; 12 (31): 17. http://www.biomedcentral.com/1472- 6963/12/31.

[10] Roberge D, Tremblay D, Turgeon MÈ, Berbiche D. 'Patients' and professionals' evaluations of quality of care in oncology outpatient clinics', Supportive Care in Cancer, 2013; 21 (11): 2983-2990.

[11] Byju KPM. Srinivasulu Y. 'Measuring service quality in private healthcare using SERVPERF scale', Journal of Management Research, 2014; 2 (1): 37-349.

[12] Miranda FJ. Chamorro A. Murillo LR Vega J. Assessing primary healthcare services quality in Spain: managers vs. patients' perceptions. The Service Industry Journal. 2010; 30 (13): 2137-2149.

[13] Longbottom D, Hilton J. Service improvement: lessons from the UK financial service sector. International Journal of Quality and Service Sciences. 2011; 3 (1): 39-59.

[14] Sliwa M, O'Kane J. 'Service quality measurement: appointment systems in UK GP Bpractices Martyna Sliwa', International Journal of Health Care Quality Assurance, 2011; 24 (6): 441-452.

[15] Basu R, Biswas D. 'A conceptual framework to identify quality attributes in healthcare organizations', International Journal of Contemporary Business Studies, 2012; 3 (12): 4552.

[16] Brady MK, Cronin JJ. 'Some new thoughts on conceptualizing perceived service quality: a hierarchical approach'. Journal of Marketing, 2001; 65 (3): 34-49.

[17] Parasuraman A, Zeithaml VA, Berry LL.. "A conceptual model of service quality and its implications for future research", Journal of Marketing, 1985; 49 (4): 41-50.

[18] Yarimoglu EK. A review of service and E-Service quality measurements: previous literature and extension. Journal of Economic and Social Studies. 2015; 5 (1): 169-200.

[19] Ghotbabadi AR, Feiz S, Baharun R. Service quality measurements: a Review. International Journal of Academic Research in Business and Social Sciences. 2015; 5 (2): 267286.

[20] Manary MP, Boulding W, Staelin R, Glickman SW. The patient experiences and health outcomes. New England Journal of Medicine. 2013; 368 (3): 201-203.

[21] Perrott BE. 'Health service delivery in Australia: gaps and solutions', Journal of General Management, 2011; 36 (3): 5566.

[22] Solomon MR. Consumer Behavior: Buying and Having. 10th ed. London: Pearson Prentice Hall; 2013.
[23] Buil I, de Chernatony L, Martinez EJ. 'Methodological issues in cross-cultural research', Journal of Targeting, Measurement and Analysis for Marketing, 2012; 20 (3/4): 223-234.

[24] Bakti IGMY, Sumaedi S. 'P-TRANSQUAL: a service quality model of public land transport services', International Journal of Quality \& Reliability Management, 2015; 32 (6): 534-558.

[25] Micuda D, Cruceru G. 'Testing SERVQUAL dimensions on the Romanian banking sector: Proceedings of the International Conference on Risk Management, Assessment and Mitigation: 2010; 329-334.

[26] Van Duong D, Binns CW, Lee AH Hipgrave DB. 'Measuring client perceived quality of maternity services in rural Vietnam', International Journal for quality in Health Care, 2004; 16 (6): 447-452.

[27] Padma P, Rajendran C, Sai LP. A conceptual framework of service quality in healthcare: perspectives of Indian patients and their attendants. Benchmarking: An International Journal. 2009; 16 (2): 157-191.

[28] Habbal Y. Patient's satisfaction and medical care service quality. International Journal of Business and Public Administration. 2011; 8 (2): 95-112.

[29] Aagja JP, Garg R. Measuring perceived service quality for public hospital (PubHosQual) in the Indian context. International Journal of Pharmaceutical and Health Care Marketing. 2010; 4 (1): 60-83.

[30] Raja, MPN, Deshmukh SG, Wadhawa S. 'Quality award dimensions: a strategic instrument for measuring health service quality', International Journal of Health Care Quality Assurance, 2007; 20 (5): 363-78.

[31] Camilleri D, O'Callaghan M. Comparing public and private care service quality. International Journal of Health Care Quality Assurance. 1998; 11 (4): 127-133.

[32] Karami M, Maleki MM, Dubinsky AJ. 'Cultural values and consumers' expectations and perceptions of service encounter quality', International Journal of Pharmaceutical and Healthcare Marketing, 2016; 10 (1): 2-26.

[33] Polsa P, Fuxiang W, Saaksjarvi M, Shuyuan P. 'Cultural values and health service quality in China, International Journal of Health Care Quality Assurance, 2013; 26 (1): 55-73.

[34] Murti A, Deshpande A, Srivastava N. 'Service quality, customer (patient) satisfaction and behavioral intention in healthcare services: exploring the Indian perspective', Journal of Health Management, 2013a; 15 (1): 29-44.

[35] Smith AM, Reynolds NL. 'Measuring cross cultural service quality: a framework for assessment", International Marketing Review, 2001; 19 (5): 450-481.

[36] Millar R. 'Framing quality improvement tools and techniques in healthcare: the case of improvement leaders' guides', Journal of Health Organization and Management, 2013; 27 (2): 209-204.

[37] Malhotra NK, Ulgado FM, Agarwal J, Baalbaki IB. 'International services marketing: a comparative evaluation of the dimensions of service quality between developed and developing countries', International Marketing Review, 1994; $11(2): 5-15$. 
[38] Mainz J. 'Quality indicators: essential for quality improvement', International Journal for Quality in Health Care, 16 (Supplement I): 2004; 11-12.

[39] Piligrimiene Z, Buciuuiene I. Exploring managerial and professional view to healthcare service quality. Journal of Economics and Management. 2011; 16: 1304-1317.

[40] Mosadeghrad AM. Healthcare service quality: towards a broad definition. International Journal of Health Care Quality Assurance. 2013; 26 (3): 203-219.

[41] WHO. African Regional Health Report. Geneva: WHO press, 2009.

[42] Bopp KD. 'How patients evaluate the quality of ambulatory medical encounters: A marketing perspective'. Journal of Health Care Marketing, 1990; 10 (1): 6-15.

[43] Grönroos C. 'The perceived service quality concept - a mistake', Managing Service Quality, 2001; 11 (3), 46-55.
[44] Donabedian A. 'Quality assessment and assurance: unity of purpose, diversity of Means', Inquiry, Spring: 1988; 175-92.

[45] Krueger, R. A. and Casey, M. A.. Focus Groups: A Practical Guide for Applied Research. 5th ed. USA: SAGE Publications, Inc, 2015.

[46] Parasuraman A, Zeithaml VA, Berry LL. A conceptual model of service quality and its implications for future research. Journal of Marketing. 1985; 49 (4): 41-50.

[47] Van Herk H, Poortinga YH, Verhallen TMM. 'Equivalence of survey data: relevance for international marketing', European Journal of Marketing, 2005; 393 (4): 351-64.

[48] Donabedian A. 2005. 'Evaluating the quality of medical care. Milbank Memorial Fund Q. Reprinted in Milbank Q, 83 (4): 691-729. 